\title{
Taguchi Grey Relational Analysis on the Mechanical Properties of Natural Hydroxyapatite: Effect of Sintering Parameters
}

Johnson Kehinde Abifarin ( $\square$ abifarinjohnsonk@yahoo.com )

Ahmadu Bello UniveaDepartment of Mechanical Engineering, Ahmadu Bello University, Zariarsity

\section{Research Article}

Keywords: Hydroxyapatite, optimization, Taguchi-grey relational analysis, sintering parameters, mechanical properties

Posted Date: April 27th, 2021

DOl: https://doi.org/10.21203/rs.3.rs-446486/v1

License: (a) (i) This work is licensed under a Creative Commons Attribution 4.0 International License.

Read Full License 


\title{
Taguchi Grey Relational Analysis on the Mechanical Properties of Natural Hydroxyapatite: Effect of Sintering Parameters
}

\author{
Johnson Kehinde Abifarin \\ a'Department of Mechanical Engineering, Ahmadu Bello University, Zaria \\ jkabifarin@abu.edu.ng
}

\begin{abstract}
Our previous study have reported synthesis and mechanical properties of natural hydroxyapatite (HA), but optimization of the measured hardness and compressive strength has not been examined. This paper presents optimization of mechanical characteristics (hardness and compressive strength), using Taguchi-grey relational analysis design. In the design, three factors with mixed levels (2 and 3) is employed with the consideration of sintering parameters (0 and $500 \mathrm{~Pa}$ compaction pressure, and 900,1000 and $1100{ }^{\circ} \mathrm{C}$ sintering temperature), reported in the previous study. The orthogonal array L18 having 18 rows corresponding to the number of tests and the required columns was selected. Results obtained shows that HA with good hardness and compressive strength is feasible with less or no compaction pressure sintering parameter. An optimum grey relational grade (GRG) of the synthesized HA is 0.7171 and has experimental value within $95 \%$ confidence interval.The optimal sintering parameters are gotten to be $500 \mathrm{~Pa}$ compaction pressure and $1100{ }^{\circ} \mathrm{C}$ sintering temperature. Result shows that sintering temperature having 99.90 percentage of contribution is the most significant factor, while compaction pressure and error are insignificant on the overall hardness and compressive strength of the synthesized HA.
\end{abstract}

Key words: Hydroxyapatite; optimization; Taguchi-grey relational analysis; sintering parameters; mechanical properties

\subsection{Introduction}

$\mathrm{Ca}_{5}\left(\mathrm{PO}_{4}\right)_{3}(\mathrm{OH}, \mathrm{F}, \mathrm{Cl})$ is the chemical formula of apatite. It is a basic component of bone, which basically encapsulates fluoroapatite, chloroapatite and hydroxyapatite. Hydroxyapatite (HA) is the steadiest type of calcium phosphate, and it is considered as quite possibly the most utilized material in bone recovery, in light of its liking to bone tissues. It has an exceptionally close comparability to the normal bone mineral [1]. The pros of HA over other material sis the simplicity of fitting its crystallinity and microstructure to suite explicit applications. Also, HA is biocompatible i.e. it is non-toxic, non-inflammatory and enhanced immunologic responses [2-5]. In recent studies, HA has been derived from natural sources [3-5].

In our previous study, reports have been made on the synthesis and mechanical properties of natural HA [4]. However, an optimization of sintering parameters have not been reported, which 
is very paramount in determining carefully optimized HA suitable for load bearing application. Taguchi Grey Relational Analysis (GRA) design is capable of optimizing multiple performance characteristics of HA. Among many DOE analysis tools, GRA is one of the foremost design methods employed when having incomplete or uncertain information [6]. To the best of our knowledge, no studies have been conducted on the use of Taguchi-GRA for the optimization of HA multiple mechanical characteristics. This study reports Taguchi-GRA on the optimization of the hardness and compressive strength of natural HA.

\subsection{Materials and Method}

\subsection{Materials, Synthesis and Sintering}

Our previous research has reported materials, synthesis, sintering and mechanical properties evaluation of HA considered in this studies [4]. The mechanical synthesis is shown in Figure 1 below:
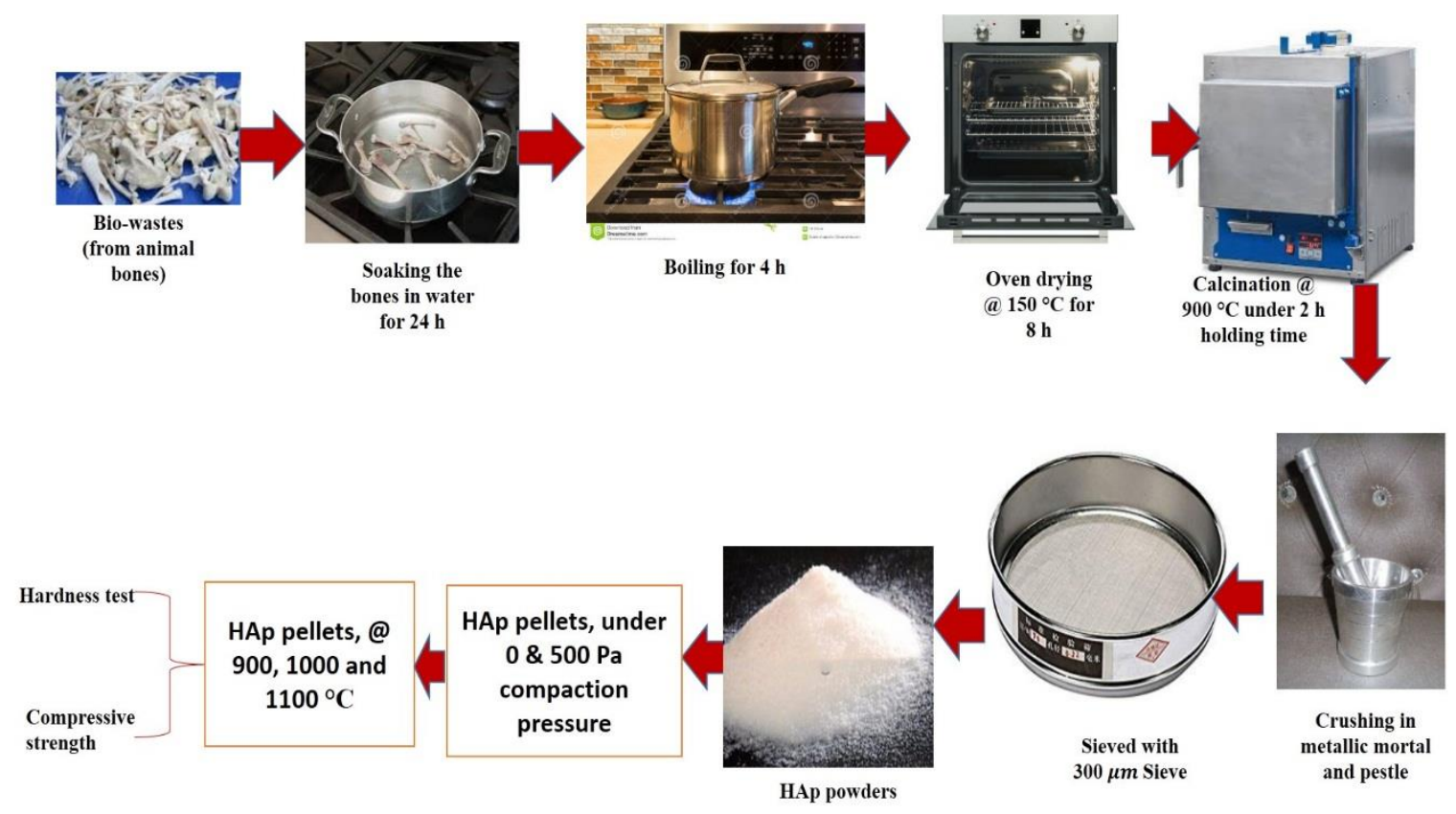

Figure 1: Experimental procedure of HA mechanical synthesis

\subsection{Methods}

\subsubsection{Taguchi DOE}

Taguchi recommends using orthogonal arrays (OA) for experiments. OA is the generalized Graeco-Latin square. The method of designing the experiment is to select the most appropriate OA and assign the parameters and interactions of interest to the appropriate columns. Use the two performance characteristics of Taguchi-GRA to determine samples with better hardness and compressive strength. Taguchi will help establish the optimal or optimal HA conditions; in order to estimate the contribution of various parameters and interactions, and to estimate the response under optimal conditions, three mixed levels of factors were selected, which were used in previous 
studies [4]. Table 1a shows the experimental design. The orthogonal array L18 selected as shown in Table $1 \mathrm{~b}$ has 18 rows, corresponding to the number of tests with the required columns, which is a function L18 (2**13**1) suitable for design existing in Minitab.

Table 1a: Taguchi Design of Experiment (DOE)

\begin{tabular}{|l|r|r|}
\hline Factors & Compaction pressure (Pa) & Sintering Temperature $\left({ }^{\circ} \mathrm{C}\right)$ \\
\hline Level 1 & 0 & 900 \\
\hline Level 2 & 500 & 1000 \\
\hline Level 3 & - & 1100 \\
\hline
\end{tabular}

Table 1b: Experimental design strategy

\begin{tabular}{|r|l|r|}
\hline Experimental no. & Compaction pressure & Sintering temperature $\left({ }^{\circ} \mathrm{C}\right)$ \\
\hline 1 & $0 \mathrm{~Pa}$ & 900 \\
\hline 2 & $0 \mathrm{~Pa}$ & 900 \\
\hline 3 & $0 \mathrm{~Pa}$ & 900 \\
\hline 4 & $0 \mathrm{~Pa}$ & 1000 \\
\hline 5 & $0 \mathrm{~Pa}$ & 1000 \\
\hline 6 & $0 \mathrm{~Pa}$ & 1000 \\
\hline 7 & $0 \mathrm{~Pa}$ & 1100 \\
\hline 8 & $0 \mathrm{~Pa}$ & 1100 \\
\hline 9 & $0 \mathrm{~Pa}$ & 1100 \\
\hline 10 & $500 \mathrm{~Pa}$ & 900 \\
\hline 11 & $500 \mathrm{~Pa}$ & 900 \\
\hline 12 & $500 \mathrm{~Pa}$ & 900 \\
\hline 13 & $500 \mathrm{~Pa}$ & 1000 \\
\hline 14 & $500 \mathrm{~Pa}$ & 1000 \\
\hline 15 & $500 \mathrm{~Pa}$ & 1000 \\
\hline 16 & $500 \mathrm{~Pa}$ & 1100 \\
\hline 17 & $500 \mathrm{~Pa}$ & 1100 \\
\hline 18 & $500 \mathrm{~Pa}$ & 1100 \\
\hline & &
\end{tabular}

\subsubsection{Grey Relational Analysis}

Grey grade generation is the first step to take in grey relational analysis. In this step, the response will be set within zero and one. From the set data, the grey coefficient will be computed to show how close the expected response is to the actual response. Then, the grey relational coefficient of all the performance characteristics corresponding to each sample treatment will be averaged to get the grey relational grade. Grey relational grade shows the overall assessment of all the multiple performance characteristics. In other word, the optimization of a single grey relational grade is the optimization of complex multiple performance characteristics. The highest grey relational grade 
level is the optimal level of the process parameter. Subsequently, statistical analysis of variance (ANOVA) is performed to determine the significance level of the employed process parameters. The best combination of the process parameters will be predicted with the help of grey grade analysis and ANOVA. Finally, a confirmation experiment is carried out to verify the best process parameters obtained from the analysis.

\subsection{Results and Discussion}

\subsection{Orthogonal Array Experimental result}

Table 2 show the experiment results of the four performance characteristics:

\begin{tabular}{|r|l|l|r|r|}
\hline $\begin{array}{l}\text { Experimental } \\
\text { no. }\end{array}$ & $\begin{array}{l}\text { Compaction } \\
\text { pressure }\end{array}$ & $\begin{array}{l}\text { Sintering } \\
\text { temperature }\end{array}$ & 900 & \multicolumn{2}{l|}{$\begin{array}{l}\text { Hardness } \\
\text { (GPa })\end{array}$} & $\begin{array}{l}\text { Compressive strength } \\
(\mathrm{MPa})\end{array}$ \\
\hline 1 & $0 \mathrm{~Pa}$ & 900 & 0.53 & 0.51 \\
\hline 2 & $0 \mathrm{~Pa}$ & 900 & 0.58 & 0.4 \\
\hline 3 & $0 \mathrm{~Pa}$ & 1000 & 0.827 & 0.44 \\
\hline 4 & $0 \mathrm{~Pa}$ & 1000 & 0.98 & 0.6 \\
\hline 5 & $0 \mathrm{~Pa}$ & 1000 & 0.708 & 0.5 \\
\hline 6 & $0 \mathrm{~Pa}$ & 1100 & 0.94 & 0.64 \\
\hline 7 & $0 \mathrm{~Pa}$ & 1100 & 0.904 & 0.79 \\
\hline 8 & $0 \mathrm{~Pa}$ & 1100 & 0.977 & 0.83 \\
\hline 9 & $0 \mathrm{~Pa}$ & 900 & 0.668 & 0.9 \\
\hline 10 & $500 \mathrm{~Pa}$ & 900 & 0.692 & 0.29 \\
\hline 11 & $500 \mathrm{~Pa}$ & 900 & 0.609 & 0.4 \\
\hline 12 & $500 \mathrm{~Pa}$ & 1000 & 0.962 & 0.33 \\
\hline 13 & $500 \mathrm{~Pa}$ & 1000 & 0.954 & 0.45 \\
\hline 14 & $500 \mathrm{~Pa}$ & 1000 & 0.87 & 0.6 \\
\hline 15 & $500 \mathrm{~Pa}$ & 1100 & 1.18 & 0.45 \\
\hline 16 & $500 \mathrm{~Pa}$ & 1100 & 1.08 & 0.7 \\
\hline 17 & $500 \mathrm{~Pa}$ & 1100 & 1.05 & 0.64 \\
\hline 18 & $500 \mathrm{~Pa}$ & & & 0.73 \\
\hline
\end{tabular}

\subsection{Grey Relational Analysis for the Multiple Performance Characteristics}

A linear data preprocessing method employed in this study for hardness and compressive strength performance characteristics is the higher the- better and is expressed as:

$x_{i}(k)=\frac{y_{i}(k)-\min y_{i}(k)}{\max y_{i}(k)-\min y_{i}(k)}$ 
Where $x_{i}(k)$ is the grey relational generation value, min $y_{i}(k)$ is the littlest estimation of $y_{i}(k)$ for the response, kth, and $\max y_{i}(k)$ is the biggest estimation of $y_{i}(k)$ for the response, $k t h$.

The grey relational generation sequences are shown in Table 3 . An ideal sequence is $\mathrm{x}_{0}(\mathrm{k})(\mathrm{k}=1$ \& 2) for hardness and compressive strength.

Table 3: Grey relational generation

\begin{tabular}{|c|c|c|}
\hline $\begin{array}{l}\text { Experimental } \\
\text { no. }\end{array}$ & Hardness & $\begin{array}{l}\text { Compressive } \\
\text { strength }\end{array}$ \\
\hline Ideal sequence & 1 & 1 \\
\hline 1 & 0.02985 & 0.06557377 \\
\hline 2 & 0 & 0.180327869 \\
\hline 3 & 0.10448 & 0.245901639 \\
\hline 4 & 0.47313 & 0.508196721 \\
\hline 5 & 0.70149 & 0.344262295 \\
\hline 6 & 0.29552 & 0.573770492 \\
\hline 7 & 0.64179 & 0.819672131 \\
\hline 8 & 0.58806 & 0.885245902 \\
\hline 9 & 0.69701 & 1 \\
\hline 10 & 0.23582 & 0 \\
\hline 11 & 0.27164 & 0.180327869 \\
\hline 12 & 0.14776 & 0.06557377 \\
\hline 13 & 0.67463 & 0.262295082 \\
\hline 14 & 0.66269 & 0.508196721 \\
\hline 15 & 0.53731 & 0.262295082 \\
\hline 16 & 1 & 0.672131148 \\
\hline 17 & 0.85075 & 0.573770492 \\
\hline 18 & 0.80597 & 0.721311475 \\
\hline
\end{tabular}

Grey relational grade is to show the relative degree of grey relation between the two sequences [xo (k) and $x i(k), i=1,2 \ldots 18 ; \mathrm{k}=1 \& 2$ ]. Equation (2) below is used to compute grey relational coefficient $(\mathrm{GRC}) \xi_{i}(k)$ :

$\xi_{i}(k)=\frac{\Delta_{\min }+\zeta \Delta_{\max }}{\Delta_{o i}(k)+\zeta \Delta_{\max }}$

Where $\Delta_{o i}(k)=\left\|\mathrm{x}_{\mathrm{o}}(\mathrm{k})-\mathrm{x}_{\mathrm{i}}(\mathrm{k})\right\|=$ difference between the absolute value of $x_{o}^{*}(\mathrm{k})$ and $x_{i}^{*}(\mathrm{k}) ; \zeta=$ distinguishing coefficient $(0 \sim 1)$, but usually assign it to each parameter an equal weight of 0.5 ; and $x_{o}^{*}(\mathrm{k})$ and $x_{i}^{*}(\mathrm{k})$ allude to reference and similarity arrangements, respectively. $\Delta_{\min }$ and $\Delta_{\max }$ are the base and most extreme deviations of every reaction variable. Table 4 shows the experimental layout of the grey relational coefficient and grade. 
As demonstrated in equation (3), the complex grey relational grade (GRG) is determined by averaging the GRC of every reaction variable:

$\gamma_{i}=\frac{1}{n} \sum_{i=1}^{n} \xi_{i}(k)$

Where $\gamma_{i}=$ the value of GRG determined for the ith experiment, $\mathrm{n}$ is the aggregate count of the performance characteristics.

Table 4: Grey relational coefficient and grade

\begin{tabular}{|c|c|c|c|c|}
\hline \multicolumn{3}{|c|}{ Grey relational coefficient (GRC) } & \multicolumn{2}{|c|}{ Grey relational grade (GRG) } \\
\hline $\begin{array}{l}\text { Experimental } \\
\text { no. }\end{array}$ & Hardness & $\begin{array}{l}\text { Compressive } \\
\text { strength }\end{array}$ & GRG values & $\begin{array}{l}\text { Average GRG for } \\
\text { each sample }\end{array}$ \\
\hline 1 & 0.3401015 & 0.348571429 & 0.34434 & \multirow{3}{*}{0.359645} \\
\hline 2 & 0.3333333 & 0.378881988 & 0.35611 & \\
\hline 3 & 0.3582888 & 0.39869281 & 0.37849 & \\
\hline 4 & 0.4869186 & 0.504132231 & 0.49553 & \multirow{3}{*}{0.500797} \\
\hline 5 & 0.6261682 & 0.432624113 & 0.5294 & \\
\hline 6 & 0.4151177 & 0.539823009 & 0.47747 & \\
\hline 7 & 0.5826087 & 0.734939759 & 0.65877 & \multirow{3}{*}{0.716973} \\
\hline 8 & 0.5482815 & 0.813333333 & 0.68081 & \\
\hline 9 & 0.6226766 & 1 & 0.81134 & \\
\hline 10 & 0.3955136 & 0.333333333 & 0.36442 & \multirow{3}{*}{0.372184} \\
\hline 11 & 0.4070474 & 0.378881988 & 0.39296 & \\
\hline 12 & 0.3697572 & 0.348571429 & 0.35916 & \\
\hline 13 & 0.6057866 & 0.40397351 & 0.50488 & \multirow{3}{*}{0.505732} \\
\hline 14 & 0.597148 & 0.504132231 & 0.55064 & \\
\hline 15 & 0.5193798 & 0.40397351 & 0.46168 & \\
\hline 16 & 1 & 0.603960396 & 0.80198 & \multirow{3}{*}{0.712739} \\
\hline 17 & 0.7701149 & 0.539823009 & 0.65497 & \\
\hline 18 & 0.7204301 & 0.642105263 & 0.68127 & \\
\hline
\end{tabular}

Optimization of hardness and compressive strength execution attributes is when the grey relational grade. Table 5 sums up the relational grade mean for each level of the utilized variables, and its complete mean. Grey relational grade diagram is shown in Figure 2, where the middle line is the total grey relational grade mean. The highest value of grey relational grade addresses the more grounded relational degree between the reference sequence $x_{0}(k)$ and the given sequence $x_{i}(k)$. The reference sequence $\mathrm{x}_{0}(\mathrm{k})$ is the best interaction reaction in the design of the experiment. The sintering parameters corresponding to the highest grey relational grade is the optimum parameter. Which means, optimization of the hardness and compressive strength execution attributes is when the grey relational grade is optimized. 
Table 5: Response table of means for GRG

\begin{tabular}{|l|l|l|l|}
\hline \multirow{2}{*}{ Factors } & \multicolumn{3}{|c|}{ GRG } \\
\cline { 2 - 4 } & Level 1 & Level 2 & Level 3 \\
\hline Compaction pressure & 0.5258 & 0.5302 & - \\
\hline Sintering temperature & 0.3659 & 0.5033 & 0.7149 \\
\hline
\end{tabular}

Mean GRG $=0.5280$

Predicted $=0.7171$

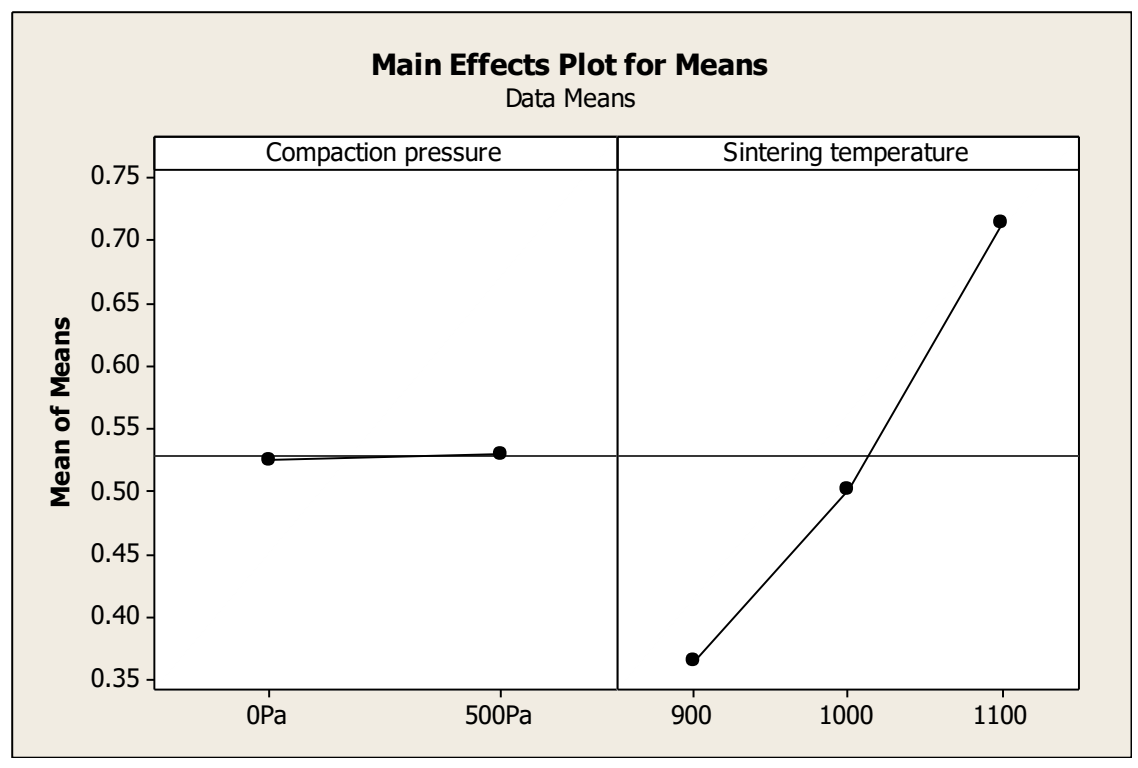

Figure 2: Grey relational grade graph

\subsection{Analysis of Variance}

The quintessence of ANOVA is to explore the variables level blend that fundamentally influences the general exhibition attributes. This was done by isolating the complete inconstancy of the grey relational grade, which is estimated by the amount of the squared deviations from the absolute mean of the grey relational grade, into commitments by each factor and the error. To start with, the absolute amount of the squared deviations SST from the total grey relational grade mean $\gamma_{m}$ can be determined using equation (4).

$S S_{T}=\sum_{j}^{p}\left(\gamma_{j}-\gamma_{m}\right)^{2}$

Where $p=$ experimental number in orthogonal array, and $\mathrm{j}=$ mean of the grey relational grade for the jth experiment. The absolute amount of the squared deviations SST is deteriorated into two sources: the amount of the squared deviations SSd because of each factor and the amount of the squared error SSe. The commitment rate by each factor blend to the absolute amount of the squared deviations SST can be utilized to assess the significance of the factor mix change on the performance characteristics. Likewise, the F test, named after Fisher [7] can likewise be utilized to figure out which factor blend significantly affect the performance characteristics. Generally, the difference in the factor mix significantly affects the performance characteristics when the $\mathrm{F}$ value 
is enormous. Aftereffects of the ANOVA (Table 5) demonstrate that sintering temperature is the main factor influencing both hardness and compressive strength. Both compaction pressing factor and error (noise) are unimportant, having 0.05 and 0.06 percentage contribution, respectively.

Table 5: ANOVA for GRG

\begin{tabular}{lllllll}
\hline Source & DOF & $\begin{array}{l}\text { Sum of } \\
\text { squares }\end{array}$ & $\begin{array}{l}\text { Mean } \\
\text { square }\end{array}$ & F & \% Contribution & Remark \\
\hline $\begin{array}{l}\text { Compaction } \\
\text { pressure }\end{array}$ & 1 & 0.000029 & 0.000029 & 0.83 & 0.05 & Insignificant \\
$\begin{array}{l}\text { Sintering } \\
\text { temperature }\end{array}$ & 2 & 0.1236 & 0.0618 & 1752.11 & 99.9 & Most significant \\
$\begin{array}{l}\text { Residual } \\
\text { error }\end{array}$ & 2 & 0.000071 & 0.000035 & & 0.06 & Insignificant \\
Total & 5 & 0.1237 & 0.06186 & & & \\
\hline
\end{tabular}

\subsection{Confirmation Test}

After the determination of optimal level of the factors, the final step is to predict and very the quality characteristics as shown in equation (5): (Ross, 1996)

$\gamma_{\text {predicted }}=\gamma_{m}+\sum_{i=1}^{q} \gamma_{0}-\gamma_{m}$

Where $\gamma_{0}$ represents the highest average value GRG at the optimal level of the sintering parameters and $\gamma_{m}$ represents the average of GRG. $\mathrm{q}$ is the number of the considered sintering parameters.

From equation (5), the predicted grey relational grade using the optimal factor parameters was computed. From response table in Table 5, using equation (5), the predicted response is 0.7171 , compared with the experimental values, which is 0.7127 , and it is the average of experimental number 16,17 and 18.

To investigate closeness of experimental result is to the predicted result, confidence interval (CI) is used in equation (6) [9]:

$$
C I=\sqrt{F_{\propto}\left(1, f_{e}\right) V_{e}\left[\frac{1}{\eta_{e f f}}+\frac{1}{R}\right]}
$$

$F_{\alpha}\left(1, f_{e}\right)=$ F ratio required for $\alpha ; \alpha=$ risk; $f_{e}=$ DOF of error; $\mathrm{V}_{\mathrm{e}}=$ variance of error; $\eta_{e f f}=$ effective number of replications, which is the equation (7) below: 
$\eta_{\text {eff }}=\frac{N}{1+(\text { total DOF of control factors })}$

$\mathrm{R}=$ number of replications when the experiment is carried out for confirmation; $\mathrm{N}=$ total number of experiments.

Therefore;

$\mathrm{V}_{\mathrm{e}}=0.000035 ; \mathrm{f}_{\mathrm{e}}=2$

Total DOF of control factors $=3$

$\mathrm{R}=1, \mathrm{~N}=18$

$\alpha=0.5$ (95\% confidence interval)

$F_{0.5}(1,2)=18.51$ (tabulated values from the F-Tables)

$\eta_{\text {eff }}=\frac{18}{1+3}=4.5$

$C I=\sqrt{18.51 \times 0.000035\left[\frac{1}{4.5}+\frac{1}{1}\right]}= \pm 0.028$

The predicted optimal grey relational grade is: $\gamma_{\text {predicted }}=0.7171$

The $95 \%$ confidence interval of the predicted optimal grey relational grade is:

$\gamma_{\text {predicted }}-C I<\gamma_{\text {experimental }}<\gamma_{\text {predicted }}+C I$

$0.6891<\gamma_{\text {experimental }}<0.7451$

The experimental grey relational grade, 0.7127 is within the confidence interval $(95 \%)$ of the predicted optimal grey relational grade.

\subsection{Microstructural confirmation}

It is important to show the microstructural characteristics of the materials as they elucidate more the effect of sintering temperature of the mechanical properties. Figure 3 shows SEM micrographs raw biowastes (RB) and the sintered $\mathrm{HA}$ at 900,1000 and $1100{ }^{\circ} \mathrm{C}$ [4]. The discrete nature morphology of RB compared to the sintered HA reflects the presence of organic materials [10]. The micrographs show that as the temperature is increased, the grain structures get closer to each other and the pores become more narrower. This effect results to increase in the mechanical properties of natural HA, i.e. increase in temperature results to increase in the mechanical properties of HA [4]. This assertion is confirmed in the employed Taguchi-Grey Relational quantitative analysis. 

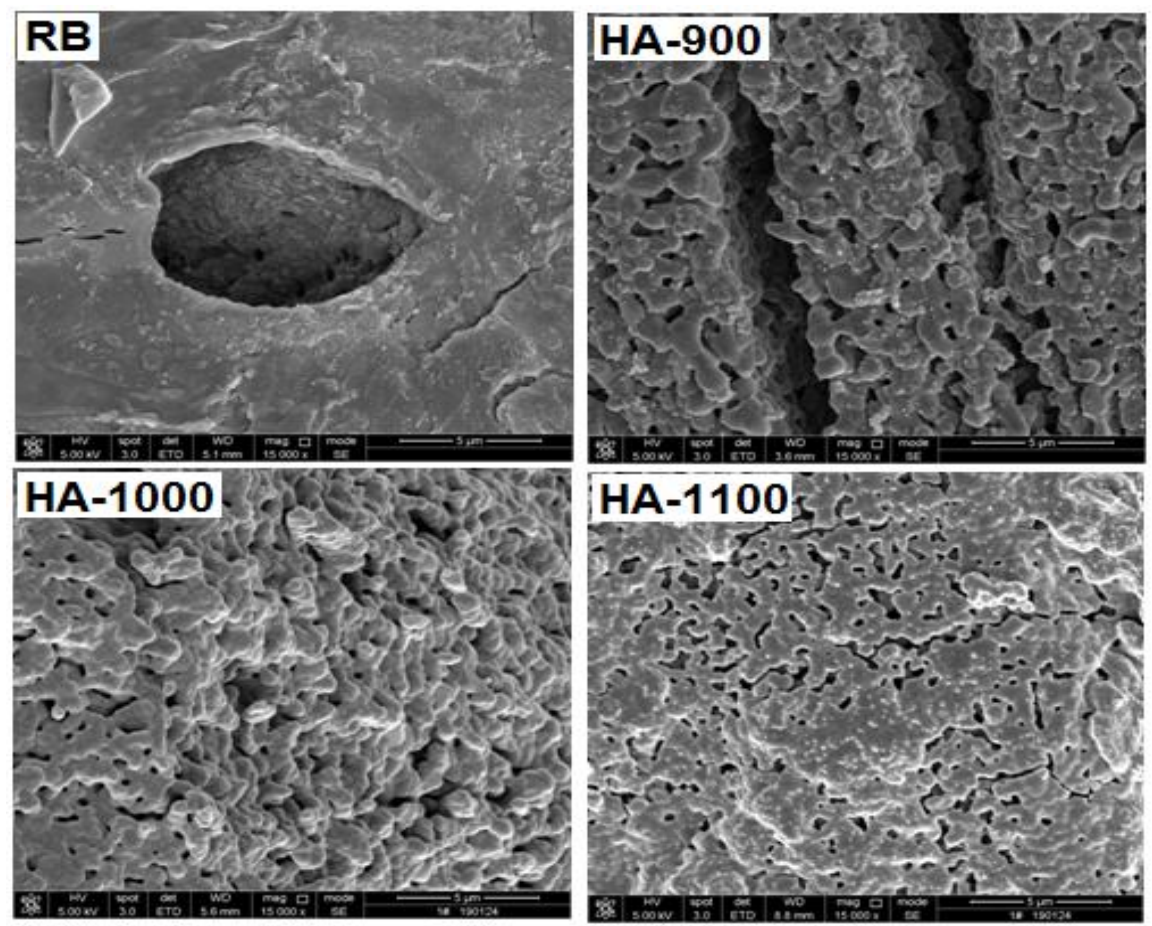

Figure 3: Microstructural characteristics of raw biowaste and the sintered HA at different temperatures [4]

\subsection{Conclusions}

Optimization investigations on the analysis of hardness and compressive strength performance characteristics of natural HA have been conducted. From Taguchi grey relational analysis of the experimental results, the following conclusions can be made:

i. Fabrication of natural HA with good hardness and compressive strength is feasible by simple hand lay-up technique.

ii. The HA has an optimum grey relational grade of 0.7171 and the validated experimental value was within $95 \%$ confidence interval.

iii. The optimal control factors (compaction pressure, sintering temperature) are set at (500Pa compaction pressure and $1100{ }^{\circ} \mathrm{C}$ sintering temperature) or (level 2, level 3).

iv. Sintering temperature is the most significant factor affecting the hardness and compressive strength performance characteristics of HA.

v. The contribution of compaction pressure and error on the overall hardness and compressive strength is observed to be insignificant.

\section{Declaration}

Funding: This research did not receive any funding

Conflicts of interest/Competing interests: The author declare no conflict of interest 
Availability of data and material: Not applicable

Code availability: Not applicable

Ethics approval: Not applicable

Consent to participate: Not applicable

Consent for publication: Not applicable

\section{References:}

[1] Vallet-Regí, M. (2006). Revisiting ceramics for medical applications. Dalton Transactions, (44), 5211-5220

[2 Ramesh, S., Loo, Z. Z., Tan, C. Y., Chew, W. K., Ching, Y. C., Tarlochan, F., ... \& Sarhan, A. A. (2018). Characterization of biogenic hydroxyapatite derived from animal bones for biomedical applications. Ceramics International, 44(9), 10525-10530.

[3] Abifarin, J. K., Obada, D. O., Dauda, E. T., \& Dodoo-Arhin, D. (2019). Experimental data on the characterization of hydroxyapatite synthesized from biowastes. Data in brief, 26, 104485.

[4] Obada, D. O., Dauda, E. T., Abifarin, J. K., Dodoo-Arhin, D., \& Bansod, N. D. (2020). Mechanical properties of natural hydroxyapatite using low cold compaction pressure: Effect of sintering temperature. Materials Chemistry and Physics, 239, 122099.

[5] Obada, D. O., Dauda, E. T., Abifarin, J. K., Bansod, N. D., \& Dodoo-Arhin, D. (2020). Mechanical measurements of pure and kaolin reinforced hydroxyapatite-derived scaffolds: A comparative study. Materials Today: Proceedings.

[6] Julong, D. (1989). Introduction to grey system theory. The Journal of grey system, 1(1), 124.

[7] Fisher, R. A. (1925). Statistical Methods for Research Workers Oliver and Boyd, London. Reprinted in Statistical Methods, Experimental Design and Scientific Inference

[8] Ross, P. J. (1996). Taguchi techniques for quality engineering: loss function, orthogonal experiments, parameter and tolerance design.

[9] Taguchi, G., \& Phadke, M. S. (1989). Quality engineering through design optimization. In Quality Control, Robust Design, and the Taguchi Method (pp. 77-96). Springer, Boston, MA.

[10] Ooi, C. Y., Hamdi, M., \& Ramesh, S. (2007). Properties of hydroxyapatite produced by annealing of bovine bone. Ceramics international, 33(7), 1171-1177. 
Figures
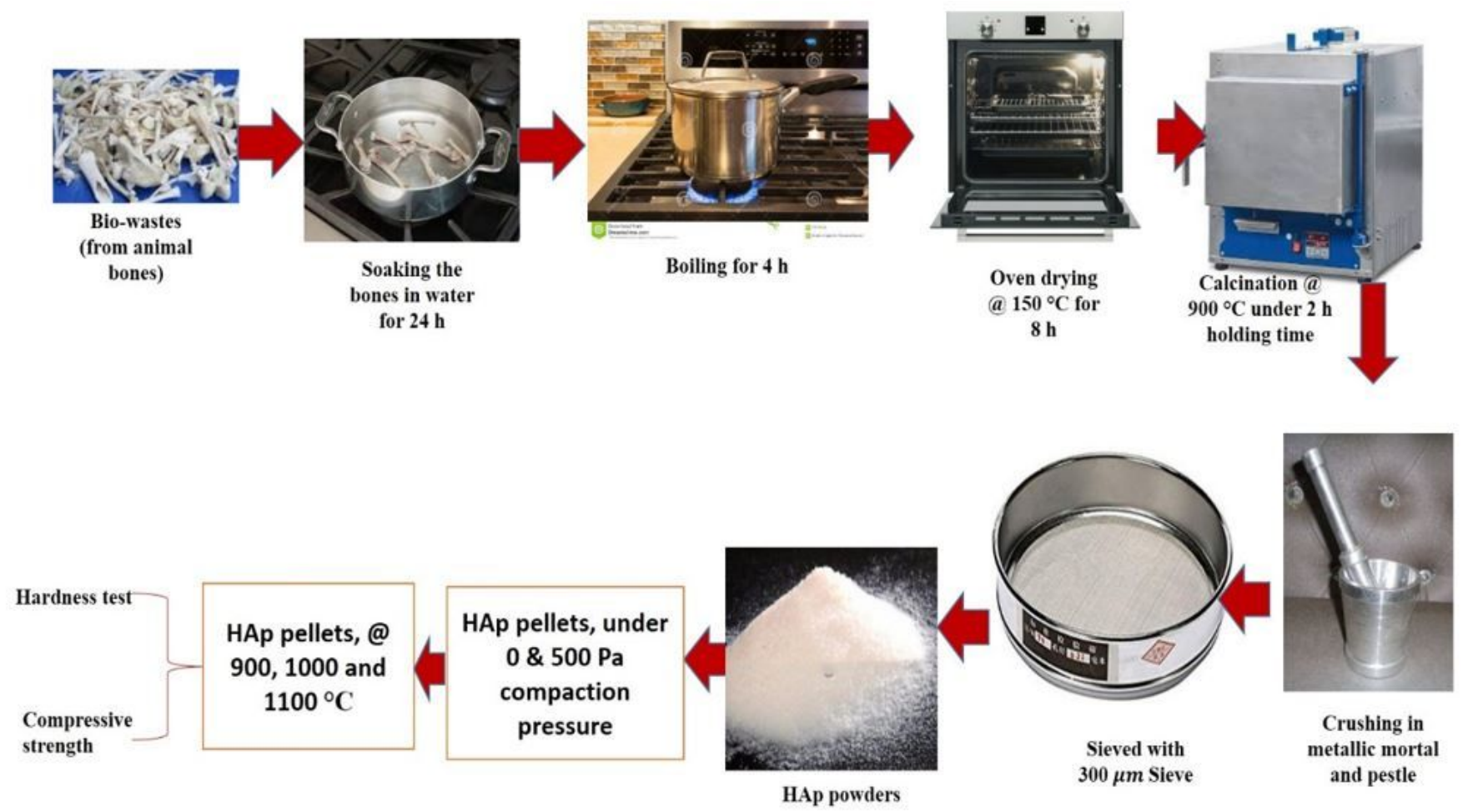

Figure 1

Experimental procedure of HA mechanical synthesis 


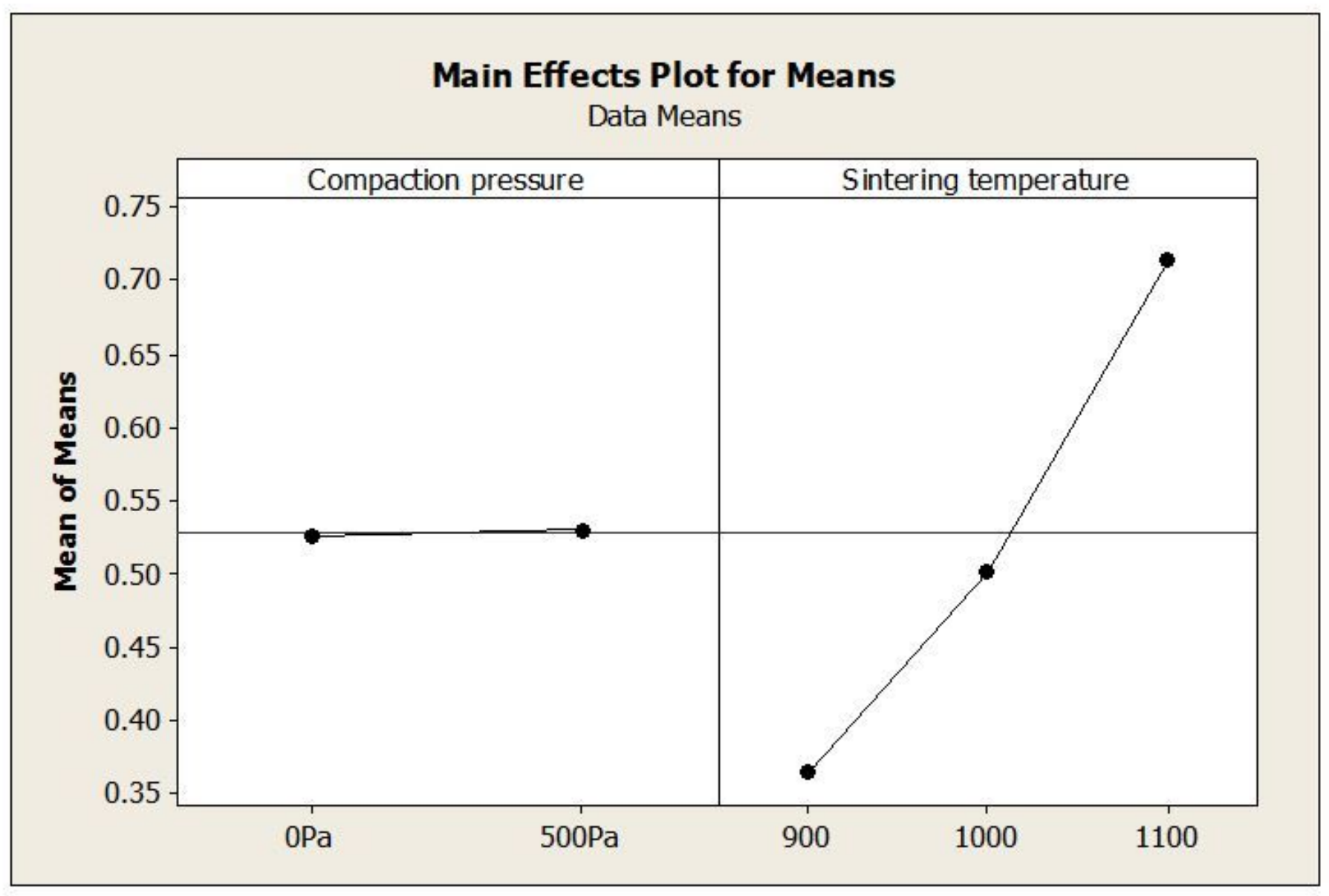

Figure 2

Grey relational grade graph 

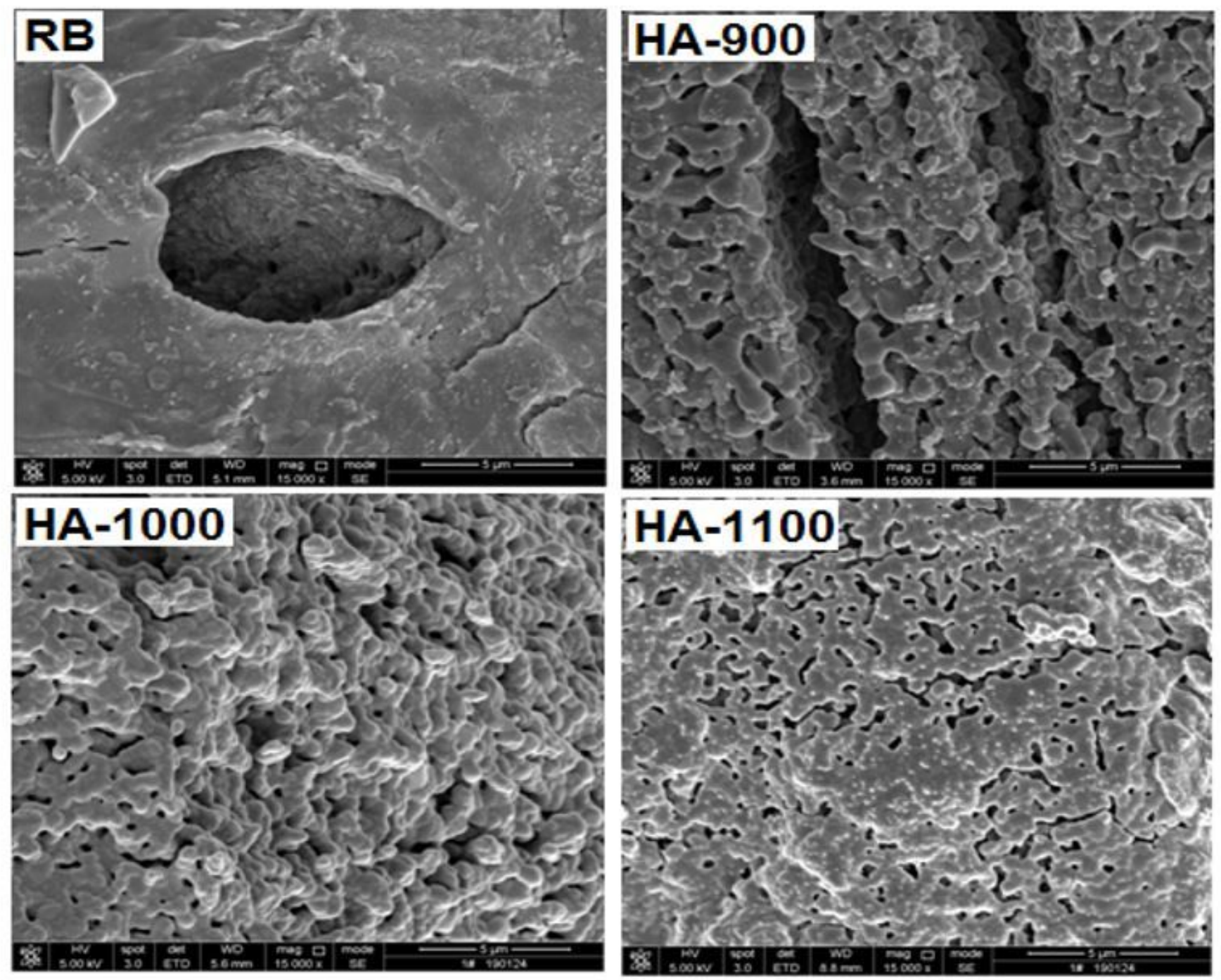

Figure 3

Microstructural characteristics of raw biowaste and the sintered HA at different temperatures [4] 